\title{
Uso de imagens Landsat 8 para análise das temperaturas superficiais do município de Imperatriz, MA
}

A presente pesquisa teve como objetivo a obtenção de mapas representativos das temperaturas superficiais do município de Imperatriz, MA a partir de imagen Landsat 8 , bem como a respectiva análise dos mesmos, verificando aspectos tanto espaciais como temporais dos dados obtidos para as datas de 7 de julho de 2014, 24 de junho de 2015 e 28 de julho de 2016. A partir dos resultados gerados, foi possível identificar a relação entre o aumento das temperaturas em certos pontos do município, muito em decorrência de áreas de solo exposto, presença de atividades agrícolas e focos de queimadas, como também a diminuição desses valores em outras áreas, a exemplo o resultado de áreas com presenças de corpos d'água, que é o caso do limite Oeste do município onde se encontra o rio Tocantins e também de áreas com vegetação mais densa, mais encontradas na área central do município. A partir disso, é possível observar que as tecnologias de geoprocessamento e sistema de informação geográfica podem se mostrar vantajosos em diversas pesquisa de âmbito ambiental, outro ponto a ser citado é a importância das áreas de cobertura vegetal em perímetros próximos a região urbana, pois equilibram o clima de forma a diminuir as condições térmicas locais.

Palavras-chave: Geoprocessamento; Landsat 8; Temperatura de superfície.

\section{Use of Landsat 8 images for analysis of surface temperatures in the municipality of Imperatriz, MA}

\begin{abstract}
The present research had as main objective the obtainment of representative maps of the surface temperatures in the microregion of Imperatriz, MA with the use of images from the Landsat 8 satellite and analysis of them verifying spatial and temporal aspects of the data obtained for the dates of July 7, 2014, 24 June 2015 and 28 July 2016. From the results generated, it was possible to identify the relationship between the increase in temperatures in certain parts of the municipality, largely due to areas of exposed soil, the presence of agricultural activities and fires, as well as the decrease in these values in other areas, for example, the result of areas with the presence of water bodies, which is the case of the western limit of the municipality where the Tocantins River is located and also of areas with denser vegetation, most found in the central area of the municipality. From this, it is possible to observe that the geoprocessing technologies and geographic information system can prove to be advantageous in several environmental researches, another point to be mentioned is the importance of the vegetation cover areas in perimeters close to the urban region, since they are balanced the climate to reduce local thermal conditions.
\end{abstract}

Keywords: Geoprocessing; Landsat 8; Surface temperature.

Topic: Geodésia, Cartografia e Sensoriamento Remoto

Reviewed anonymously in the process of blind peer
Received: 05/06/2021

Approved: 26/06/2021
George Fernandes Azevedo (iD

Universidade Federal do Maranhão, Brasil

http://lattes.cnpq.br/3259343585706307

http://orcid.org/0000-0002-2207-7282

gf.azevedo@ufma.br

\section{Lucas Leite Santos}

Universidade Federal do Maranhão, Brasil http://lattes.cnpq.br/1559133487789453

lucas.leite@discente.ufma.br

Raul de Jesus Costa Bezerra (it)

Universidade Federal do Maranhão, Brasil http://lattes.cnpq.br/9628372967534168 http://orcid.org/0000-0001-9655-6369 raul.jcb@discente.ufma.br
Referencing this:

AZEVEDO, G. F.; SANTOS, L. L.; BEZERRA, R. J. C.. Uso de imagens Landsat 8 para análise das temperaturas superficiais do município de Imperatriz, MA. Revista Ibero Americana de Ciências Ambientais, v.12, n.6, p.233-245, 2021. DOI: http://doi.org/10.6008/CBPC2179$\underline{6858.2021 .006 .0020}$ 


\section{INTRODUÇÃO}

As temáticas das mudanças climáticas globais têm sido enfatizadas pelos meios midiáticos nas últimas décadas, onde as principais discussões giram em torno dos prováveis efeitos que essas mudanças geram no meio ambiente, pois o clima é um fator preponderante na configuração geográfica, composição do ambiente e disponibilidade de recursos naturais (MUINGA et al., 2017).

De acordo com Teodoro et al. (2008), as mudanças climáticas estão presentes na dinâmica do planeta desde a sua formação e são causadas por fatores naturais, sem a necessidade de interferências humanas, e antrópicos, causados pela ação do homem, que são objetos de estudo no meio científico, no qual há discordância sobre o grau de influência desses fatores nas alterações climáticas do planeta.

De acordo com Oliveira et al. (2018), os três principais fatores naturais para a alteração da temperatura terrestre são: a emissão de radiação solar, causadora das variações solares, como os ciclos de Schwabe; a recepção da radiação, determinada pela posição terrestre em relação ao sol; e as alterações na composição atmosférica, como a formação de nuvens e de gases de efeito estufa, vegetação e circulação oceânica, que resultam no aumento da temperatura das regiões.

Por outro lado, os fatores antrópicos estão relacionados ao crescimento da indústria, aumento da frota de veículos automotores e aumento do índice de degradação ambiental como queimadas para a crescente demanda populacional, que causam um elevado nível de emissão de dióxido de carbono na atmosfera terrestre contribuindo, assim, para o aumento do efeito estufa e acarretando no aumento do aquecimento global (LIMA, 2016).

As consequências do aumento da temperatura global no planeta seriam o derretimento das águas congeladas na cobertura de montanhas e geleiras, elevação do nível dos oceanos, expansão térmica da água e aumento das nuvens e chuvas, ou seja, as características ambientais do planeta seriam modificadas, ocasionando em diferentes regiões eventos como inundações, deslizamentos de terra, alterações nas condições atmosféricas e problemas na agricultura e pecuária (CENCI et al., 2020). Segundo relatórios do IPCC (2007), a temperatura do planeta está aumentando gradativamente cerca de $0,7^{\circ} \mathrm{C}$, tendo como principal motivo a emissão de gases de efeito estufa, provenientes das crescentes atividades humanas.

Carvalho et al. (2011) destacam que essas mudanças estão, de fato, relacionadas aos fatores que alteram o estado do clima, essas variações são identificadas por testes analíticos e estatísticos, que mostram as mudanças nas médias ou nas variabilidades de suas propriedades climáticas, que podem persistir por décadas.

No Brasil, no período de 1960 a 2002, foi observado que nas principais estações meteorológicas houve um aumento considerável na temperatura, sendo de $0,5^{\circ} \mathrm{C}$ a $0,8^{\circ} \mathrm{C}$ nas temperaturas mínimas e 0,4 ${ }^{\circ}$ C nas temperaturas máximas. Segundo dados estatísticos do anuário climatológico do Brasil, feito em 2018, a temperatura máxima anual esteve $0,4{ }^{\circ} \mathrm{C}$ acima do normal climatológico, enquanto a média anual e a mínima anual se mostraram $0,7^{\circ} \mathrm{C}$ acima do normal (RAMOS et al. 2018). Nobre et al. (2007) destacaram que o aumento da temperatura no Brasil pode causar alterações nos biomas, principalmente no Leste da 
Amazônia e Nordeste brasileiro, causando substituição da vegetação da floresta amazônica por vegetação de cerrado e vegetação de caatinga do sertão nordestino por vegetação de regiões áridas.

Guimarães et al. (2016) estabelecem em seu trabalho sobre as projeções climáticas no Nordeste brasileiro, que as perspectivas para essa região brasileira se referem ao aumento da temperatura em todos os aspectos, apresentando temperaturas maiores nos meses usualmente mais quentes. Como é o caso do Estado do Maranhão, onde Silva et al. (2016) destacam que os índices de temperatura do ar indicam forte tendência de aumento na maioria das estações nos períodos chuvoso e seco em todas as estações do estado. As consequências, assim como em outros estados brasileiros, podem se concretizar com alterações dos índices de temperatura e precipitação, alterações dos recursos hídricos afetando o abastecimento humano, geração de energia e até mesmo na agricultura local (NOBREGA, 2008).

Autores como Wanderley et al. (2019) sugerem que o processo de urbanização tem o potencial de alterar características térmicas das superfícies dos grandes centros urbanos, proporcionando o aumento da temperatura local ocasionado por fatores como uso do solo, alterações dos recursos naturais para geração de energia e água e a emissão de gases do efeito estufa, que estão muitas vezes ligados ao aumento da população urbana e consequentemente as alterações do clima local.

Ortiz et al. (2011) afirmam que a falta de planejamento urbano nas cidades tem uma parcela direta nos problemas ambientais, pois as alterações humanas com o meio urbano e proximidades geram novas alterações "terra-atmosfera". O uso do solo para ampliação industrial, aumento do fluxo móvel e das construções residenciais, juntamente com a má gestão de resíduos sólidos, acarretam em mudanças de energia na atmosfera devido a emissão de gases poluentes, gerando assim as ilhas de calor.

O fenômeno das ilhas de calor e a elevação exacerbada da temperatura em ambientes urbanos interferem de maneira direta na qualidade de vida das pessoas. Problemas como desconforto térmico das residências e ondas de calor passam a ser frequentes nas localidades, ganhando uma maior intensidade nos meses de verão (ESTEVAM et al., 2019).

Segundo Azevedo et al. (2017), as ilhas de calor podem ser percebidas ao longo do dia, porém, tem maior intensidade durante a noite, pois tem um resfriamento mais lento em comparação com as áreas rurais. Na parte da manhã e da tarde, as calçadas, asfaltos, muros e telhados absorvem grande parte da energia solar e os materiais liberam calor durante a noite. De acordo com Fialho (2012), a diferença entre a superfície urbana, em relação ao campo, ocasiona a discrepância entre o tempo de absorção da energia solar disponível durante o dia e a remissão da energia terrestre à noite, que tem como principal consequência o resfriamento mais lento da cidade, tornando o evento mais intenso no período da noite.

Diante dos fatos citados, torna-se necessário um estudo do detalhamento das ilhas de calor urbanas para fornecer subsídios à gestão territorial e ao planejamento urbano, visando a sustentabilidade da sociedade, para que seja possível a construção de cidades mais saudáveis para seus habitantes (AMORIM, 2019). Fialho (2012) destaca que uma das possibilidades de identificação de uma ilha de calor corresponde ao uso de imagens de satélite, que permitem observações, leituras e análises do ambiente urbano através de correlações dos parâmetros climáticos. 
Neste contexto, o sensoriamento remoto é uma ferramenta muito útil nos estudos de cunho ambiental, uma vez que a pesquisa relacionada ao clima dentro das metrópoles tem ganhado destaque nas últimas décadas (BARBOSA et al., 2009). E o sensoriamento remoto apresenta a vantagem da possibilidade de integrar informações sobre os vários processos físicos e biológicos em diferentes escalas de tempo e espaço, permitindo a geração de parâmetros físicos da superfície terrestre e a obtenção de dados detalhados das regiões estudadas (NOVO et al., 2005).

O presente trabalho teve como foco principal a análise da temperatura superficial na região do município de Imperatriz, no estado do Maranhão, pela utilização de imagens do sensor TIRS presente no satélite Landsat 8. As análises foram realizadas a partir da geração de mapas temáticos de temperaturas superficiais da região de estudo e da observação temporal e espacial, buscando assim uma comparação entre os resultados obtidos para averiguar o padrão de crescimento ou redução dos índices de temperatura da região.

\section{MATERIAIS E MÉTODOS}

A metodologia do estudo correspondeu ao desenvolvimento de seis etapas principais que foram: 1 obtenção das imagens do satélite Landsat 8, obtidas no portal Earth Explorer; 2 - criação de um banco de dados e projeto específicos no software Spring; 3 - importação das imagens; 4 - conversão dos níveis de cinza para radiância, e determinação dos valores de temperatura superficial referentes as imagens importadas; 5 - criação dos mapas temáticos e recorte dos mesmos; 6 - análise dos resultados de temperatura obtidos a partir dos mapas criados. Todas essas etapas citadas serão detalhadas a seguir.

\section{Área de Estudo}

A cidade de Imperatriz, ilustrada na figura 1, está localizada na Mesorregião do Oeste Maranhense, inserida na microrregião de Imperatriz, abrangendo uma área de $1.369 \mathrm{~km}^{2}$ (IBGE, 2018). O município apresenta uma população de aproximadamente 259.337 habitantes (IBGE, 2020) A região tem um predomínio de formação de floresta mista, possuindo bioma Amazônico e Cerrado, fazendo divisa com o estado do Tocantins (SANTOS et al., 2018).

A microrregião apresenta um clima tropical superúmido, com temperaturas médias entre $24^{\circ} \mathrm{C}$ e $29^{\circ}$ C, média pluviométrica anual de $1500 \mathrm{~mm}$ e uma vegetação dividida entre cerrado, floresta, mata e campo (MENEZES, 2009). Em relação as atividades econômicas estão a pecuária, o extrativismo vegetal, a lavoura permanente e a lavoura temporária, as transferências governamentais, o setor empresarial com 5.258 unidades atuantes e o trabalho informal são as principais fontes de recursos para o município (CORREIA FILHO, 2011).

De acordo com Santos et al. (2019), no ano de 2018, a região de Imperatriz apresentava uma área urbana de $42,05 \mathrm{~km}^{2}, 25,41 \%$ maior em relação aos anos 2000 . A área de vegetação densa correspondia à $9,90 \mathrm{~km}^{2}$, com $22,53 \%$ de redução em território em relação a 2000 , a qual se concentra mais ao Sul do município e à Sudeste, além de uma vegetação rasteira de $37,94 \mathrm{~km}^{2}$, que apresentou uma redução de $38 \%$ 
em relação a 2000, que se concentra mais aos limites municipais.
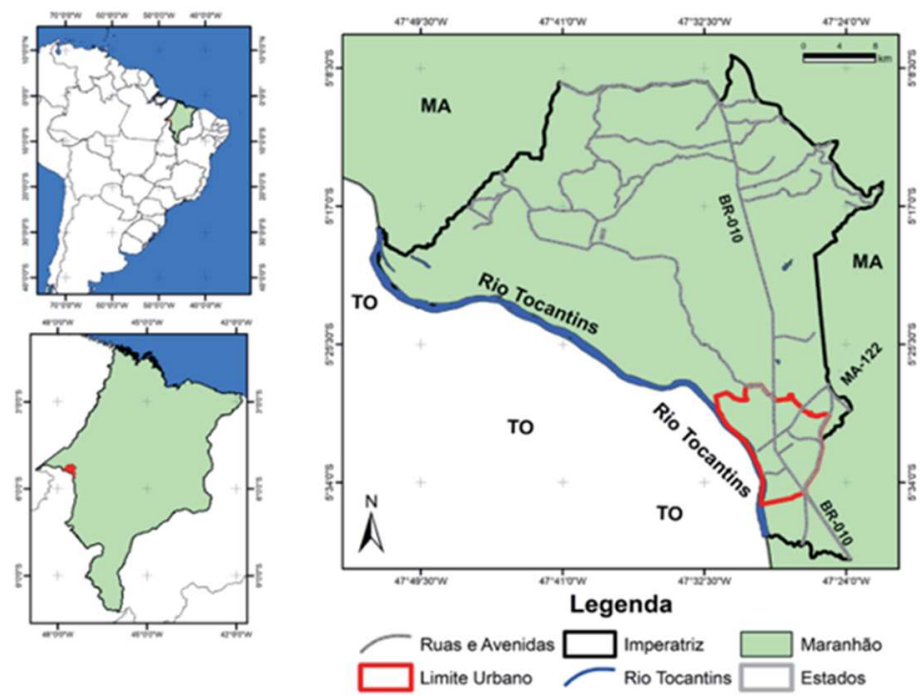

Figura 1: localização do município de Imperatriz - MA. Fonte: IBGE (2018); IMESC (2021); Santos et al. (2018).

\section{Materiais utilizados}

Para o desenvolvimento deste trabalho foram utilizadas imagens do satélite Landsat 8 , sensor Operational Land Imager (OLI), para as datas de 7 de julho de 2014, 2 de junho de 2015 e 28 de julho de 2016, obtidas gratuitamente no portal EarthExplorer da USGS (United States Geological Survey). O critério para a escolha das imagens baseou-se no mínimo de cobertura de nuvens possível, para que as mesmas não interferissem na criação dos mapas temáticos e na análise dos resultados. Os dados utilizados no processo referem-se à banda 11 das imagens, conforme a descrição: Banda 11 - Infravermelho Termal/TIRS 2 (11.5 $12.51 \mu \mathrm{m}) 100 \mathrm{~m}$ - tratada e disponibilizada com pixel de 30 metros.

Para o tratamento das imagens obtidas e referida criação dos mapas temáticos, foi utilizado o software Spring, versão 5.5.6, e para criação dos mapas finais foi utilizado o Qgis, versão 2.18.0. Para uma melhor visualização e comparação entre os mapas criados e a área de estudo, foi utilizado o Google Earth Pro.

\section{Procedimentos metodológicos}

Inicialmente foi criado um banco de dados onde, posteriormente dentro do mesmo, foi criado um projeto referente a área dessa pesquisa e voltado para a estruturação das informações espaciais essenciais para a elaboração das análises. Destacam-se as seguintes informações referentes às principais características deste projeto: Projeção e Datum utilizados: UTM/ SIRGAS2000; Retângulo envolvente estabelecido em coordenadas planas: $\mathrm{X} 1=176.497,7852 \mathrm{~m} ; \mathrm{Y} 1=242.153,1930 \mathrm{~m} ; \mathrm{X} 2=9.374 .386,0330 \mathrm{~m} ; \mathrm{Y} 2=$ 9.436.174,9028 m;

Após a criação do banco de dados e seu projeto foi realizada, sequencialmente, a importação das imagens (em formato TIFF/GEOTIFF) para o software Spring, com a categoria anteriormente criada CAT_Imagem, e seus nomes correspondentes, identificando cada data pelo ano correspondente. Após isso, 
foi realizado a geração das imagens da categoria do tipo Modelo Numérico do Terreno, que foi utilizado para a criação das imagens e mapas de temperatura.

O passo seguinte foi a conversão dos níveis de cinza para radiância das cenas que os representam, obtidos pela aplicação da Equação 1, dada por:

$$
\mathbf{L}_{11}=\mathbf{M L} * \mathbf{B}_{11}+\mathbf{A L} \quad(1)
$$

Onde:

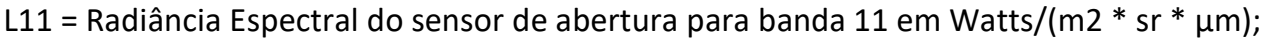
$\mathrm{ML}=$ Fator multiplicativo de redimensionamento da banda 11 igual a 0.0003342 ; B11 = valor quantizado calibrado pelo pixel em DN para a banda 11;

$\mathrm{AL}=$ Fator de redimensionamento aditivo especifico da banda 11 igual a 0.1.

Essa equação foi implementada computacionalmente utilizando-se da linguagem LEGAL, presente no software SPRING.

As imagens resultantes do processo foram sendo salvas, sequencialmente, em modelo numérico (MNT), onde as mesmas já foram convertidas para a unidade Celsius, utilizando-se da Equação 2 dada a seguir.

$$
\operatorname{Temp} C=\left(\frac{K_{2}}{\log \left(\left(\frac{K_{1}}{L_{11}}\right)+1\right)}\right)-273
$$
Onde: K1 = Constante de calibração $1=480.8883(\mathrm{~K})$; K2 = Constante de calibração $2=1201.1442$ (K).

Criadas as matrizes de temperatura, foi realizado o passo seguinte de criação dos mapas temáticos a partir do fatiamento da grade numérica de temperatura. Para isso, foram criadas, inicialmente, categorias temáticas para cada data correspondente do estudo. Dentro de cada categoria, e de acordo com os dados de temperatura (mínima e máxima) gerados anteriormente para cada data, foram criadas classes temáticas, que correspondem à divisão das temperaturas em escalas, onde adotou-se divisão em 5 classes para cada data, para promover a apresentação equitativa em termos de representação.

Com os mapas temáticos criados, foi feito o recorte de cada um deles considerando o limite do município, onde para isso foi criada uma classe LIMITE que abrangia o contorno exato do mesmo.

Após a criação dos mapas temáticos e posterior recorte dos mesmos, foram iniciadas as análises com base nos resultados de temperaturas obtidos. Duas análises foram realizadas, uma análise temporal e outra espacial. Temporalmente, foram analisadas as mudanças nas temperaturas entre os anos, considerando determinadas partes do território que está sendo estudado que apresentem redução ou aumento significativos nos valores de temperatura. Afim de facilitar essa análise foram criadas imagens obtidas a partir da diferença entre os planos de informação de temperatura para cada ano, obtidas ao longo dos processos de criação dos mapas temáticos. De forma espacial foi feita a análise da distribuição das temperaturas dentro de cada ano específico, verificando temperaturas extremas em pontos específicos e buscando possíveis causas para esse fenômeno. 


\section{RESULTADOS E DISCUSSÃO}

\section{Análise Espacial}

Inicialmente, foi realizada a análise espacial da distribuição das temperaturas, considerando cada ano individualmente. A partir do mapa da data de 7 de julho de 2014, observou-se que a maior parte das maiores temperaturas (entre $27^{\circ} \mathrm{C}$ e $30,3^{\circ} \mathrm{C}$ ) se apresentam na área central da cidade de Imperatriz (ao Sul do território municipal), a qual é caracterizada por grande concentração populacional e cuja densidade populacional e a comercialização são intensos. Em contrapartida, as áreas com menores temperaturas encontram-se mais espalhadas pelas regiões Leste e Oeste do município, e também em certa porção do Norte, regiões caracterizadas por menor concentração de população e maior presença de vegetação. Na região Oeste do município, na divisa com o estado do Tocantins, onde encontra-se o rio Tocantins, se observa a predominância de baixas temperaturas (entre $18{ }^{\circ} \mathrm{C}$ e $21^{\circ} \mathrm{C}$ ). Em certo ponto do mapa, na parte Norte do município, foram encontradas temperaturas superficiais elevadas (entre $27^{\circ} \mathrm{C}$ a $30,3^{\circ} \mathrm{C}$ ) resultantes de área destinadas ao plantio e de vegetação mais rasteira, onde a presença da vegetação mais densa é muito baixa. A Figura 2 ilustra a distribuição das temperaturas superficiais para a data de 07/07/2014.

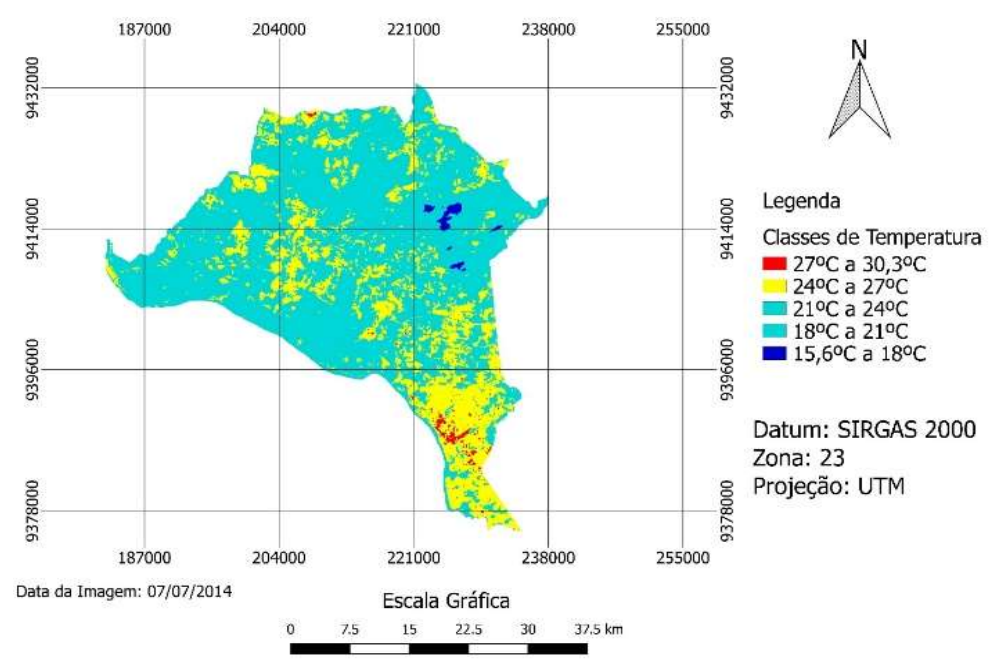

Figura 2: Carta de temperatura superficial de imperatriz - MA na data de 07/07/2014.

Para a data de 24 de junho de 2015 houve uma grande predominância e distribuição da classe de temperaturas superficiais com valores mais elevados (entre $29,5^{\circ} \mathrm{C}$ e $32,6{ }^{\circ} \mathrm{C}$ ) na área da cidade de Imperatriz como um todo. Na parte mais ao Sul do município encontra-se a cidade, onde a concentração populacional é muito elevada e a presença de vegetação é menor, por isso a presença das maiores temperaturas no local. Na parte Norte, estão distribuídas as áreas características de plantações, onde são realizadas queimadas e limpeza de vegetação para a realização dessa atividade, por isso a presença de focos de temperaturas mais altas. Na parte central do município, caracterizada por área de maior presença de vegetação, também foram verificados focos espalhados de temperaturas elevadas, muito devido a ocorrência de incêndios naturais nessa região. Temperaturas mais baixas (entre $20,2{ }^{\circ} \mathrm{C}$ e $23,3{ }^{\circ} \mathrm{C}$ ) foram verificadas mais nas partes Oeste (devido a presença do rio Tocantins) e Leste do município. A Figura 3 ilustra a distribuição das temperaturas 
superficiais para a data de 24/06/2015.

Levando em conta o mapa criado da data de 28 de julho de 2016, observou-se temperaturas muito elevadas (entre $33,9^{\circ} \mathrm{C}$ e $36,8^{\circ} \mathrm{C}$ ) distribuídas por todo o território do município. Houve uma presença muito grande dessas temperaturas elevadas na parte mais populosa do município (região Sul) e arredores da cidade (devido aos bairros mais distantes). A Figura 4 ilustra a distribuição das temperaturas superficiais para a data de $28 / 07 / 2016$.

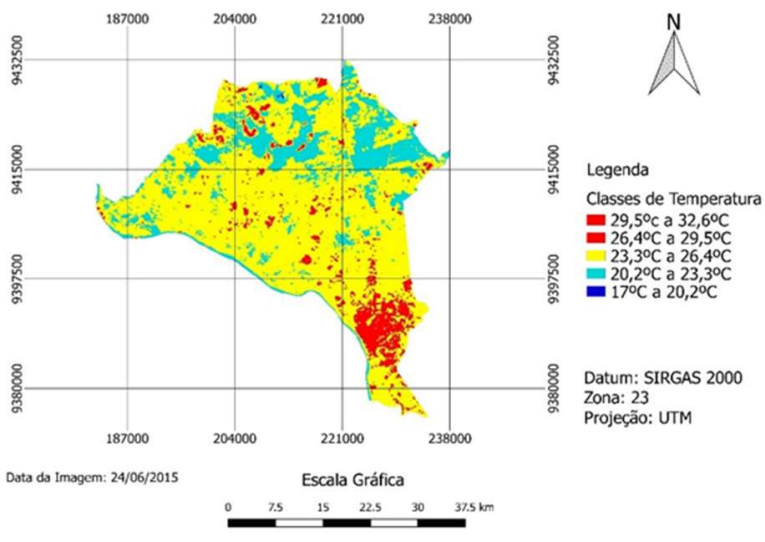

Figura 3: Carta de temperatura superficial de imperatriz - MA na data de 24/06/2015.

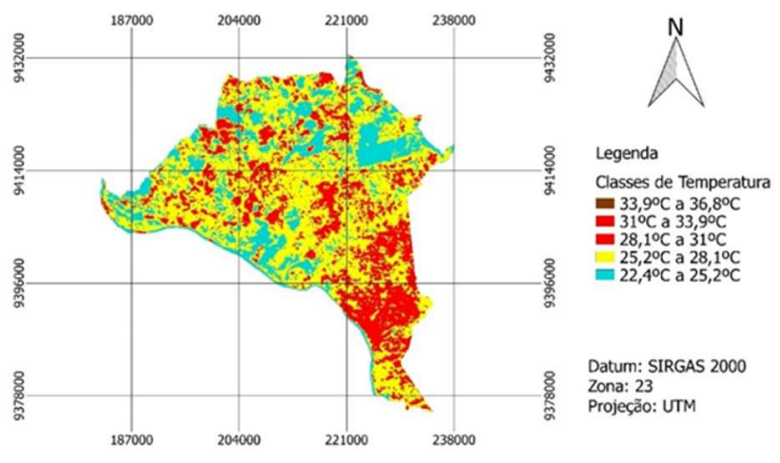

Data da Imagem: 28/07/2016 Escala Gráfica

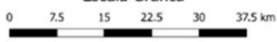

Figura 4: Carta de temperatura superficial de imperatriz - MA na data de 26/07/2016.

\section{Análise Temporal}

Para a realização de uma análise temporal, foram necessários dados climáticos complementares. Nas Tabelas de 1 a 3, pode-se observar os dados, disponibilizados pelo INMET - Instituto Nacional de Meteorologia, da Estação de Imperatriz - MA, na Tabela de Dados das Estações Meteorológicas Brasileiras ${ }^{1}$, que dispõe de dados diários sobre o clima nas proximidades das estações. Assim, encontram-se disponíveis os valores correspondentes à temperatura, umidade, vento, índices de radiação e pluviosidade local. Foram analisados os dados da parte final da manhã e do período da tarde, os quais apresentam, comumente, as maiores temperaturas diárias.

Em função das informações, no dia 07/07/2014, a estação meteorológica da cidade de Imperatriz apresentou uma média diária de $27,03^{\circ} \mathrm{C}$ e média de temperatura máxima de $29,8{ }^{\circ} \mathrm{C}$, umidade média de $58,1 \%$, rajadas de vento de $6,4 \mathrm{~km} / \mathrm{h}$ e radiação apresentou uma média de $1613,58 \mathrm{~W} / \mathrm{m}^{2}$. A relação entre temperatura e umidade do ar, mostrou que a amplitude térmica da cidade não foi tão alta devido as máximas de umidade local. As rajadas de vento, mesmo com baixos valores apresentados, permaneceram durante todo o período de maior radiação solar, amenizando a sensação térmica local. O índice pluviométrico do local foi de $0 \mathrm{~mm}$ na data de estudo. A média de radiação solar transmitida para a superfície também foi menor que os anos de 2015 e 2016 apresentando, assim, uma média térmica menor em toda a região de Imperatriz. Apesar de a estação se localizar em um ponto especifico do perímetro urbano, os dados disponíveis são usados para verificação do clima de toda a região.

\footnotetext{
${ }^{1}$ Tabela disponível no portal do Instituto Nacional de Meteorologia (INMET).
} 
Tabela 1: Dados climáticos do dia 07/07/2014 das estações automáticas meteorológicas de Imperatriz - MA.

\begin{tabular}{|c|c|c|c|c|c|c|c|c|c|c|}
\hline \multirow{2}{*}{ DATA } & \multirow{2}{*}{ HORA } & \multicolumn{3}{|c|}{ Temperatura $\left({ }^{\circ} \mathrm{C}\right)$} & \multicolumn{3}{|l|}{ Umidade (\%) } & \multirow{2}{*}{\begin{tabular}{|l|} 
Vento $(\mathrm{Km} / \mathrm{h})$ \\
Rajadas \\
\end{tabular}} & \multirow{2}{*}{ Radiação $\left(\mathrm{W} / \mathrm{m}^{2}\right)$} & \multirow{2}{*}{ Chuva (mm) } \\
\hline & & Instantânea & Max & $\min$ & Instantânea & Max & Min & & & \\
\hline $07 / 07 / 2014$ & $10: 00$ & 20,6 & 20,6 & 19,8 & 89 & 90 & 88 & 1,6 & 33,16 & 0 \\
\hline $07 / 07 / 2014$ & $11: 00$ & 24,2 & 24,3 & 20,6 & 74 & 89 & 74 & 2,8 & 532,39 & 0 \\
\hline $07 / 07 / 2014$ & $12: 00$ & 26,9 & 27 & 24 & 61 & 76 & 61 & 2,8 & 1435,24 & 0 \\
\hline $07 / 07 / 2014$ & $13: 00$ & 30,9 & 31,4 & 26,9 & 42 & 61 & 41 & 6,4 & 2078,48 & 0 \\
\hline $07 / 07 / 2014$ & $14: 00$ & 32,2 & 32,7 & 30,7 & 37 & 43 & 34 & 9,6 & 2542,76 & 0 \\
\hline $07 / 07 / 2014$ & $15: 00$ & 32,7 & 33 & 31,9 & 34 & 38 & 34 & 9,2 & 2819,19 & 0 \\
\hline $07 / 07 / 2014$ & $16: 00$ & 34 & 34,5 & 32,6 & 32 & 35 & 32 & 9,4 & 2860,38 & 0 \\
\hline $07 / 07 / 2014$ & \begin{tabular}{|l|}
$17: 00$ \\
\end{tabular} & 33,8 & 34,9 & 33,6 & 30 & 33 & 29 & 9,4 & 2607,05 & 0 \\
\hline
\end{tabular}

Na data de 24/06/2015, as médias de temperatura máxima foram menores que as médias da data anterior estudada na estação meteorológica de Imperatriz, apresentando uma média máxima de $29,75{ }^{\circ} \mathrm{C}$, porém as temperaturas instantâneas foram maiores e a temperatura média diária apresentou um valor de $27,2{ }^{\circ} \mathrm{C}$, mostrando que a temperatura superficial e a sensação térmica fossem maiores que a do ano de 2014. A diferença visível entre os mapas de 2014 e 2015, se dá pelo fato de que a medição da estação é usada como base para toda a região, dessa forma a medição fora do perímetro urbano, onde se localiza a estação, pode apresentar valores maiores ou menores que a medica oficial. A umidade apresentou valores parecidos nas primeiras horas onde a radiação era maior, porém apresentou médias valores maiores ao término da tarde. A radiação apresentou uma média de $1349,92 \mathrm{~W} / \mathrm{m}^{2}$ e as rajadas de vendo foram de $4,1 \mathrm{~km} / \mathrm{h}$ sendo menores que no ano de 2014. A média pluviométrica, assim como em 2014, também foi de 0, pois não houve chuvas no período estudado.

Tabela 2: Dados climáticos do dia 24/06/2015 das estações automáticas meteorológicas de Imperatriz - MA.

\begin{tabular}{|c|c|c|c|c|c|c|c|c|c|c|}
\hline \multirow{2}{*}{ DATA } & \multirow{2}{*}{ HORA } & \multicolumn{3}{|c|}{ Temperatura $\left({ }^{\circ} \mathrm{C}\right)$} & \multicolumn{3}{|l|}{ Umidade (\%) } & \multirow{2}{*}{$\begin{array}{l}\text { Vento }(\mathrm{Km} / \mathrm{h}) \\
\text { Rajada }\end{array}$} & \multirow{2}{*}{ Radiação $\left(\mathrm{W} / \mathrm{m}^{2}\right)$} & \multirow{2}{*}{ Chuva (mm) } \\
\hline & & Instantânea & Max & Min & Instantânea & Max & Min & & & \\
\hline $24 / 06 / 2015$ & $10: 00$ & 20,3 & 20,3 & 19,6 & 90 & 91 & 90 & 1,3 & 40,73 & 0 \\
\hline $24 / 06 / 2015$ & $11: 00$ & 23,6 & 23,7 & 20,3 & 80 & 90 & 80 & 1,8 & 460,93 & 0 \\
\hline $24 / 06 / 2015$ & $12: 00$ & 27,6 & 27,7 & 23,5 & 62 & 81 & 62 & 1,9 & 1394,98 & 0 \\
\hline $24 / 06 / 2015$ & $13: 00$ & 30,3 & 30,3 & 27,6 & 52 & 62 & 52 & 3,1 & 2002,89 & 0 \\
\hline $24 / 06 / 2015$ & $14: 00$ & 32,6 & 33 & 30,3 & 38 & 52 & 38 & 5,4 & 2461,47 & 0 \\
\hline $24 / 06 / 2015$ & $15: 00$ & 32,2 & 33,6 & 32 & 42 & 42 & 34 & 5,9 & 2195,34 & 0 \\
\hline $24 / 06 / 2015$ & $16: 00$ & 34,2 & 34,5 & 31,5 & 33 & 45 & 32 & 7,3 & 2036,6 & 0 \\
\hline $24 / 06 / 2015$ & $17: 00$ & 34,3 & 34,9 & 32,8 & 33 & 34 & 30 & 6,3 & 2243,07 & 0 \\
\hline
\end{tabular}

Para a data de 2016 , a média diária de temperatura foi de $30,45^{\circ} \mathrm{C}$ e a média máxima foi de $27,03^{\circ} \mathrm{C}$ em relação a estação meteorológica. A temperatura durante o dia já vai de acordo com o mapa gerado, pois o território da região de Imperatriz, em sua maior porcentagem, está apresentando altas temperaturas. A média de umidade foi de 44,5 \% apresentando um valor seguro, enquanto a radiação apresentou uma média de $1611,40 \mathrm{~W} / \mathrm{m}^{2}$, sendo maior que a de 2015 e menor que a de 2014. As rajadas de vendo apresentaram valores de $5,38 \mathrm{~km} / \mathrm{h}$ e a média pluviométrica, assim como nos anos anteriores foi de 0 , já que o período de estiagem é bem definido na região de Imperatriz.

Tabela 3: Dados climáticos do dia 28/07/2016 das estações automáticas meteorológicas de Imperatriz - MA.

\begin{tabular}{|c|c|c|c|c|c|c|c|c|c|c|}
\hline \multirow{2}{*}{ DATA } & \multirow{2}{*}{ HORA } & \multicolumn{3}{|c|}{ Temperatura $\left({ }^{\circ} \mathrm{C}\right)$} & \multicolumn{3}{|l|}{ Umidade (\%) } & \multirow{2}{*}{$\begin{array}{l}\text { Vento (Km/h) } \\
\text { Rajada }\end{array}$} & \multirow{2}{*}{ Radiação (W/m²) } & \multirow{2}{*}{ Chuva (mm) } \\
\hline & & Instantânea & Max & Min & Instantânea & Max & Min & & & \\
\hline $28 / 07 / 2016$ & $10: 00$ & 17,8 & 20,8 & 16,8 & 73 & 80 & 70 & 2,3 & 50,09 & 0 \\
\hline $28 / 07 / 2016$ & $11: 00$ & 22,2 & 22,4 & 17,8 & 53 & 73 & 52 & 2,6 & 694,32 & 0 \\
\hline $28 / 07 / 2016$ & $12: 00$ & 27,6 & 27,7 & 22,2 & 38 & 53 & 37 & 2,6 & 1582,26 & 0 \\
\hline
\end{tabular}




\begin{tabular}{|l|l|l|l|l|l|l|l|l|l|l|}
$28 / 07 / 2016$ & $13: 00$ & 30,8 & 30,8 & 27,6 & 35 & 39 & 35 & 3,4 & 2249,57 & 0 \\
\hline $28 / 07 / 2016$ & $14: 00$ & 33,1 & 33,3 & 30,7 & 27 & 35 & 26 & 9,2 & 2711,93 & 0 \\
\hline $28 / 07 / 2016$ & $15: 00$ & 33,4 & 34,4 & 32,9 & 24 & 27 & 23 & 9,6 & 2919,88 & 0 \\
\hline $28 / 07 / 2016$ & $16: 00$ & 34,5 & 35,3 & 33,3 & 24 & 25 & 23 & 7,5 & 2929,79 & 0 \\
\hline $28 / 07 / 2016$ & $17: 00$ & 35,7 & 35,9 & 34,5 & 20 & 24 & 19 & 5,9 & 2683,27 & 0 \\
\hline
\end{tabular}

A diferença entre os planos de informação das temperaturas foi outra análise temporal realizada. Primeiramente foi feita uma análise entre as datas de 7 de julho de 2014 e 24 de junho de 2015, onde foi criado um mapa representando a diferença de temperaturas superficiais para essas datas, como mostra a Figura 5.

A partir da Figura 5, observa-se que as áreas onde foram registrados focos com maiores valores de mudança das temperaturas (na faixa de $5^{\circ} \mathrm{C}$ a $9{ }^{\circ} \mathrm{C}$ ), tomando por base as datas relacionadas, foram nas regiões Norte e Nordeste do município. Foram verificados aumentos nos valores de temperaturas em alguns pontos na parte Sul da região, onde se concentram a zona urbana do município. Houve um ponto de maior diminuição de temperatura $\left(-9^{\circ} \mathrm{C}\right.$ a $\left.-5{ }^{\circ} \mathrm{C}\right)$ na parte Norte, e também outros pontos distribuídos ao Norte, Sul e parte central do território que apresentam diminuição na faixa de $-5^{\circ} \mathrm{C}$ a $0^{\circ} \mathrm{C}$. De forma geral, as mudanças de temperatura em grande parte do território municipal encontram-se na classe de temperatura de $0{ }^{\circ} \mathrm{C}$ a 5 ${ }^{\circ} \mathrm{C}$, onde a maior predominância dessa mudança foi na região Leste do município, no limite entre Imperatriz e Tocantins. A Tabela 4 mostra a relação entre as classes de temperaturas e suas correspondentes áreas de influência, para a diferença entres as datas de 24/06/2015 e 07/07/2014.

Tabela 4: Medida de classes para a diferença dos mapas de temperatura entre 2015 e 2014.

\begin{tabular}{|l|l|}
\hline Classes de Temperatura & Áreas de Influência $\left(\mathrm{Km}^{2}\right)$ \\
\hline$-9^{\circ} \mathrm{C}$ a $-5^{\circ} \mathrm{C}$ & 0,22 \\
\hline$-5{ }^{\circ} \mathrm{C}$ a $0^{\circ} \mathrm{C}$ & 37,63 \\
\hline $0{ }^{\circ} \mathrm{C}$ a $5{ }^{\circ} \mathrm{C}$ & 1314,92 \\
\hline $5{ }^{\circ} \mathrm{C}$ a $9^{\circ} \mathrm{C}$ & 17,82 \\
\hline Total & $\mathbf{1 3 7 0 , 6 1}$ \\
\hline
\end{tabular}

A partir da Tabela 4 pode-se perceber que a classe que apresentou maior influência territorial $\left(1314,921 \mathrm{~km}^{2}\right)$ foi a de $0{ }^{\circ} \mathrm{C}$ a $5{ }^{\circ} \mathrm{C}$, como já mencionada anteriormente na análise da Figura 5 . A Figura 6 apresenta as diferenças de temperaturas superficiais entre as datas 28/07/2016 e 24/06/2015.

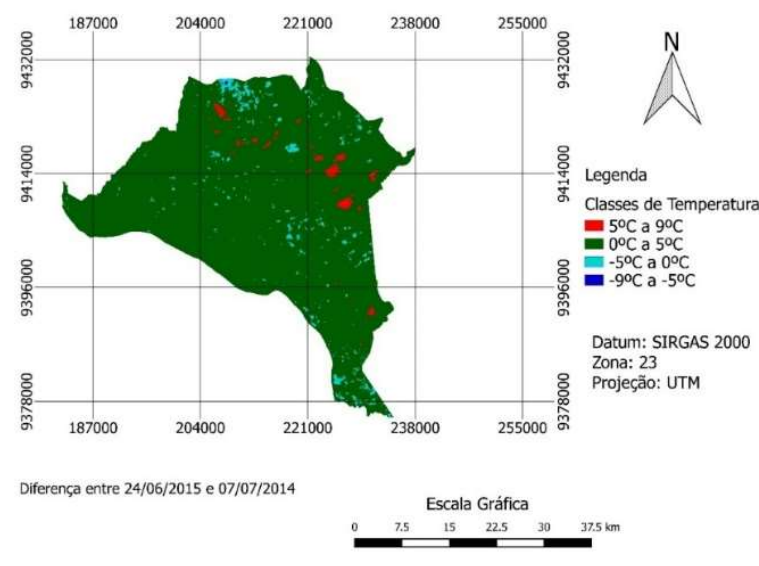

Figura 5: Carta com as diferenças de temperaturas superficiais entre as datas 24/06/2015 e 07/07/2014.

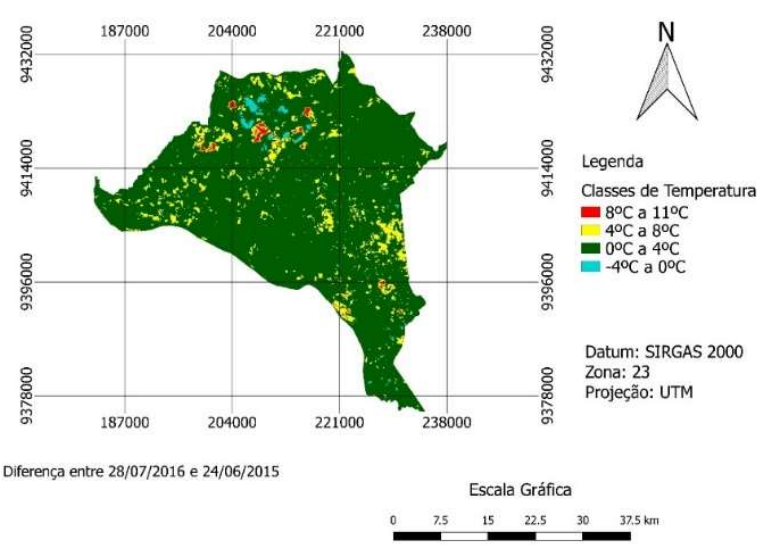

Figura 6: Carta com as diferenças de temperaturas superficiais entre as datas 28/07/2016 e 24/06/2015

A partir da Figura 6, observa-se que os pontos onde houve o registro dos maiores aumentos nos 
valores de temperatura, da classe de $8{ }^{\circ} \mathrm{C}$ a $11{ }^{\circ} \mathrm{C}$, encontram-se na região Norte e em alguns pontos específicos na cidade de Imperatriz, parte mais ao Sul do município. Maiores diminuições das temperaturas também são identificadas em alguns pontos da parte Norte do município, onde as mesmas encontram-se na classe de $-4{ }^{\circ} \mathrm{Ca} 0{ }^{\circ} \mathrm{C}$. Em outros pontos encontram-se alguns registros da classe de temperatura de $4{ }^{\circ} \mathrm{C}$ a 8 ${ }^{\circ} \mathrm{C}$, mas em grande parte do território do município há certa predominância de mudanças de temperatura da classe de $0{ }^{\circ} \mathrm{C}$ a $4{ }^{\circ} \mathrm{C}$, como pode ser visualizada na Figura 6 apresentada. A Tabela 2 mostra a relação entre as classes de temperaturas e suas correspondentes áreas de influência, para a diferença entres as datas de 28/07/2016 e 24/06/2015.

Tabela 5: Medida de classes para a diferença dos mapas de temperatura entre 2015 e 2014.

\begin{tabular}{|l|l|}
\hline Classes de Temperatura & Áreas de Influência $\left(\mathbf{K M}^{2}\right)$ \\
\hline$-4{ }^{\circ} \mathrm{C}$ a $0{ }^{\circ} \mathrm{C}$ & 14,27 \\
\hline $0^{\circ} \mathrm{C}$ a $4{ }^{\circ} \mathrm{C}$ & 1242,47 \\
\hline $4^{\circ} \mathrm{C}$ a $8{ }^{\circ} \mathrm{C}$ & 105,64 \\
\hline $8^{\circ} \mathrm{C}$ a $11^{\circ} \mathrm{C}$ & 8,27 \\
\hline Total & 1370,66 \\
\hline
\end{tabular}

A partir da Tabela 5 pode-se perceber que a classe que apresentou maior influência territorial $\left(1242,47 \mathrm{~km}^{2}\right)$ foi a de $0{ }^{\circ} \mathrm{C}$ a $4{ }^{\circ} \mathrm{C}$, como já mencionada anteriormente na análise da Figura 6.

Fazendo uma comparação entre as Tabela 4 e 5 percebe-se que houveram diferenças significativas nas áreas de influências e correspondentes classes de temperaturas das mesmas. A classe de temperatura de $-5^{\circ} \mathrm{C}$ a $0{ }^{\circ} \mathrm{C}$ da Tabela 4 apresentou um valor de $37,63 \mathrm{~km}^{2}$ de área de influência correspondente a ela que, se comparada com a classe de $-4{ }^{\circ} \mathrm{C}$ a $0{ }^{\circ} \mathrm{C}$ da Tabela 5 , a qual apresentou $14,27 \mathrm{~km}^{2}$, resulta que houveram mais áreas que apresentaram essa diminuição de temperatura nos anos relacionados pela Tabela 4 . Na classe de $0{ }^{\circ} \mathrm{C}$ a $5{ }^{\circ} \mathrm{C}$ da Tabela 4, que apresentou $1314,92 \mathrm{~km}^{2}$ de área de influência, se comparada a classes de 0 ${ }^{\circ} \mathrm{C}$ a $4{ }^{\circ} \mathrm{C}$ da Tabela 5 de 1242,47 km² de área de influência, também se observasse um aumento significativo de áreas com esse aumento de temperatura entre os anos relacionados pela Tabela 4.

A maior diferença registrada entre os valores das áreas de influência foi entre as classes de $5{ }^{\circ} \mathrm{C}$ a 9 ${ }^{\circ} \mathrm{C}$ da Tabela 4, com $17,82 \mathrm{~km}^{2}$ de área, e a classe de $4{ }^{\circ} \mathrm{C}$ a $11{ }^{\circ} \mathrm{C}$ da Tabela 5 , com $113,91 \mathrm{~km}^{2}$ de área de influência. Essa última comparação indica um incremento expressivo territorial que apresentaram um aumento da temperatura entre os anos de 2016 e 2015.

\section{CONCLUSÕES}

A partir dos resultados obtidos neste trabalho, verifica-se o quão importante é a utilização das imagens de satélites, e dos dados que podem ser derivados destas informações. A análise comportamental das temperaturas superficiais de determinadas áreas representada como exemplo para o município de Imperatriz - MA, foco de nossa pesquisa, deixa isso evidente. Por meio dos resultados obtidos foi possível observar, de forma clara, a relação entre as temperaturas superficiais e a variação da cobertura vegetal do município, e as influências nos valores de temperaturas espaciais e temporais que essa relação proporciona, além do fator de focos de incêndios naturais e artificiais.

Algumas áreas apresentaram aumentos significativos de temperatura, decorrentes de presença de 
solo exposto, vegetação rasteira ou de queimadas locais realizadas pelo homem, que tem como objetivo de promover a prática do plantio no local, ou mesmo de incêndios naturais. Outras áreas apresentaram diminuição ou conservação dos valores de temperatura ao longo do período analisado em decorrência de se caracterizarem como áreas com presença de corpo d'água, como no limite Oeste do município onde encontra-se o rio Tocantins, e de áreas com vegetação mais acentuada, como na parte mais central do território, ou mesmo áreas de plantio irrigadas, presentes mais na parte Norte do município.

Vale ressaltar que as temperaturas que foram obtidas a partir das imagens Landsat estão relacionadas às temperaturas superficiais locais, diferentemente da temperatura do ar obtidas pelos sensores das estações meteorológicas. Apesar disso, este processo de obtenção de temperaturas proporciona a avaliação de aspectos ambientais de extensas regiões com custo reduzido e de forma razoavelmente rápida.

\section{REFERÊNCIAS}

AMORIM, M. C. C. T.. Ilhas De Calor Urbanas: métodos e técnicas de análise. Revista Brasileira de Climatologia, v.15, p.22-47, 2019. DOI: http://dx.doi.org/10.5380/abclima.v0i0.65136

AZEVEDO, A. C.; DUARTE, C. C.; FERREIRA, G. G.; TORRES, Í. B. S.; SILVA, M. E. A.; DUARTE, C. C.. Illhas de Calor e Ilhas de Frescor: uma abordagem direcionada para a sala de aula. Revista Diálogos, v.1, n.17, p.213-231, 2017. Dol: http://dx.doi.org/10.13115/2236-1499.v1n17p213

BARBOSA, R. V. R.; VECCHIA, F. A. S.. Estudos de ilha de calor urbana por meio de imagens do Landsat 7 ETM+: Estudo de caso em São Carlos (SP). Revista Minerva, v.6, n.3, p.273278, 2009

CARVALHO, J. L. R.; MACHADO, M. N. M.; MEIRELLES, A. M.. Mudanças climáticas e aquecimento global: implicações na gestão estratégica de empresas do setor siderúrgico de minas gerais. Cadernos Ebape.Br, v.9, n.2, p.220-240, 2011. DOI: http://dx.doi.org/10.1590/s1679-39512011000200002

CENCI, D. R.; LORENZO, C.. A mudança climática e o impacto na produção de alimentos: alguns elementos de análise da realidade brasileira e argentina. Revista Direito em Debate, v.29, n.54, p.32-43, 2020. DOI:

http://dx.doi.org/10.21527/2176-6622.2020.54.32-43

CORREIA FILHO, F. L.. Projeto Cadastro de Fontes de Abastecimento por Água Subterrânea, estado do Maranhão: relatório diagnóstico do município de Imperatriz. Teresina: CPRM - Serviço Geológico do Brasil, 2011.

ESTEVAM, A. L. D.; OLIVEIRA, J. S.. Ilhas de calor no Bairro Cajazeiras: estudo de caso na cidade de Salvador, Bahia, Brasil. Geopauta, v.3, n.3, p.75-88, 2019. DOI: http://dx.doi.org/10.22481/rg.v3i3.5697

FIALHO, E. S.. Ilha de calor: reflexões acerca de um conceito. Revista Acta Geográfica, p.61-76, 2012. DOI: http://dx.doi.org/10.5654/actageo2012.0002.0004

GUIMARÃES, S. O.; COSTA, A. A.; VASCONCELOS JÚNIOR, F. C.; SILVA, E. M.; SALES, D. C.; ARAÚJO JÚNIOR, L. M.; SOUZA,
S. G.. Projeções de Mudanças Climáticas sobre o Nordeste Brasileiro dos Modelos do CMIP5 e do CORDEX. Revista Brasileira de Meteorologia, v.31, n.3, p.337-365, 2016. DOI: http://dx.doi.org/10.1590/0102-778631320150150

IBGE. Instituto Brasileiro de Geografia e Estatística. Área territorial brasileira. Rio de Janeiro: IBGE, 2018.

IBGE. Instituto Brasileiro de Geografia e Estatística. Estimativa da população residente no Brasil e unidades da federação com data de referência em 10 Julho de 2020. Rio de Janeiro: IBGE, 2020.

IPCC. Cambio climático 2007: Informe de síntesis. Contribución de los Grupos de trabajo. Genebra: OMM, 2007.

IMESC. Instituto Maranhense de Estudos Socioeconômicos e Cartográficos. Enciclopédia dos Municípios Maranhenses: região de desenvolvimento do Tocantins Maranhense. São Luís: IMESC, 2021.

LIMA, R. P.. A Ação Antrópica como Propulsora das Mudanças Climáticas na Região Nordeste. Revista Tocantinense de Geografia, v.5, n.8, p.91-102, 2016. DOI: http://dx.doi.org/10.22241/2317-9430/rtg.v5n8p91-102

MENEZES, R. H. N.. Caracterização agroclimática e análise do rendimento agrícola do Estado do Maranhão, Brasil. Tese (Doutorado) - Universidade Federal de Campina Grande, Campina Grande, 2009.

MUINGA, N. M.; GALATTO, S. L.. Mudanças climáticas globais e seus impactos no meio ambiente. Geografia em Questão, Marechal Cândido Rondon, v.10, n.02, p.121-124, 2017.

NOBRE, C. A.. Mudanças Climáticas Globais e o Brasil: Porque Devemos nos preocupar. Boletim da Sociedade Brasileira de Meteorologia, v.30, p.7-11, 2007.

NOVO, E. M. L. M.; FERREIRA, L. G.; BARBOSA, C.; CARVALHO, C.; SANO, E. E.; SHIMABUKURO, Y.; HUETE, A.; POTTER, C.; ROBERTS, D. A.; HESS, L. L; MELACK, J. J.; YOSHIOKA, H.; KLOOSTER, S.; KUMAR, V.; MYNENI, R.; 
RATANA, P.; DIDAN, K.; MIURA, T.. Técnicas avançadas de sensoriamento remoto aplicadas ao estudo de mudanças climáticas e ao funcionamento dos ecossistemas amazônicos. Acta Amazônica, v.35, n.2, p.259-272, 2005. DOI: http://dx.doi.org/10.1590/s0044-59672005000200016

OLIVEIRA, M. J.; CARNEIRO, C. R.; VECCHIA, F. A. S.; BAPTISTA, G. M. M.. Ciclos climáticos e causas naturais das mudanças do clima. Terrae Didatica, v.13, n.3, p.149, 2018. DOI: http://dx.doi.org/10.20396/td.v13i3.8650958

ORTIZ, G. F.; AMORIM, M. C. C. T.. Ilhas de calor em Cândido Mota/SP: algumas considerações. Revista Formação, v.1, n.18, p.238-257, 2011

RAMOS, A. M.; ALVES, L.; DINIZ, A. F.; MARENGO, J. A.. Anuário Climático do Brasil. São José dos Campos, 2018.

SANTOS, R. L.; NUNES, F. G.. Imperatriz do Maranhão: proposição para a compreensão do processo de ocupação e consolidação da cidade. Geotextos, v.14, n.2, p.117-141, 2018. DOI: http://dx.doi.org/10.9771/geo.v14i2.26988

SANTOS, M. R.; MARTINEZ, M. A.; ZONTA, J. H.. Modelos para Determinação de Fósforo e Nitrato em Neossolo Quartzarênico e Latossolo Vermelho Usando TDR. Geoamazonia, v.7, n.13, p.68-84, 2019. DOI: http://dx.doi.org/10.17551/2358-1778/geoamazonia

SILVA, F. B.; SANTOS, J. R. N.; FEITOSA, F. E. C. S.; SILVA, I. D. C.; ARAUJO, M. L. S.; GUTERRES, C. E.; SANTOS, J. S.; RIBEIRO, C. V.; BEZERRA, D. S.; NERES, R. L.. Evidências de Mudanças Climáticas na Região de Transição AmazôniaCerrado no Estado do Maranhão. Revista Brasileira de Meteorologia, v.31, n.3, p.330-336, 2016. DOI: http://dx.doi.org/10.1590/0102-778631320150149

TEODORO, P. H. M.; AMORIM, M. C. C. T.. Mudanças Climáticas: algumas reflexões. Revista Brasileira de Climatologia, v.3, n.1, p.25-35, 2008. DOI: http://dx.doi.org/10.5380/abclima.v3i0.25405

WANDERLEY, H. S.; FERNANDES, R. C.; CARVALHO, A. L.. Aumento das temperaturas extremas na cidade do Rio de Janeiro e o desvio ocasionado durante um evento de El Niño intenso. Revista Brasileira de Geografia Física, v.12, n.4, p.1291-1301, 2019. DOI: http://dx.doi.org/10.26848/rbgf.v12.4.p1291-1301

A CBPC - Companhia Brasileira de Produção Científica (CNPJ: 11.221.422/0001-03) detém os direitos materiais desta publicação. Os direitos referem-se à publicação do trabalho em qualquer parte do mundo, incluindo os direitos às renovaç̃oes, expansões e disseminações da contribuiç̃o, bem como outros direitos subsidiários. Todos os trabalhos publicados eletronicamente poderão posteriormente ser publicados em coletâneas impressas sob coordenação da Sustenere Publishing, da Companhia Brasileira de Produção Científica e seus parceiros autorizados. Os (as) autores (as) preservam os direitos autorais, mas não têm permissão para a publicação da contribuição em outro meio, impresso ou digital, em português ou em tradução. 